\title{
Estimation of seismic spectral acceleration in Peninsular India
}

\author{
S T G RAghu KANTH ${ }^{1}$ and R N IYENGAR ${ }^{2}$ \\ ${ }^{1}$ Department of Civil Engineering, Indian Institute of Technology, Guwahati 781 039, India. \\ e-mail: rk@iitg.ernet.in \\ ${ }^{2}$ Department of Civil Engineering, Indian Institute of Science, Bangalore 560 012, India. \\ e-mail: rni@civil.iisc.ernet.in
}

\begin{abstract}
Peninsular India (PI), which lies south of $24^{\circ} \mathrm{N}$ latitude, has experienced several devastating earthquakes in the past. However, very few strong motion records are available for developing attenuation relations for ground acceleration, required by engineers to arrive at rational design response spectra for construction sites and cities in PI. Based on a well-known seismological model, the present paper statistically simulates ground motion in PI to arrive at an empirical relation for estimating 5\% damped response spectra, as a function of magnitude and source to site distance, covering bedrock and soil conditions. The standard error in the proposed relationship is reported as a function of the frequency, for further use of the results in probabilistic seismic hazard analysis.
\end{abstract}

\section{Introduction}

The importance of estimating seismic hazards in Peninsular India (PI), which is an intra-plate region, needs no special emphasis. The frequent occurrence of devastating earthquakes in this part of India has been a reminder that engineers have to use seismological approaches to estimate region specific design ground motion, instead of relying on rules of thumb and ad hoc seismic zones. However, analytical source mechanism models are not simple enough to be directly applicable in engineering problems. There have been attempts to develop semi-empirical approaches, based on the available database, that can be projected to the future in a statistical sense. Popularly, ground motion and the consequent hazards are described in terms of peak ground acceleration (PGA). However, it is well recognized that $\mathrm{PGA}$ does not uniquely influence damage in man-made structures. Hence, engineers prefer the response spectrum as a better descriptor of seismic hazard. This is a frequency domain representation of the ground motion, having the additional advantage of providing the design engineer with an insight into how structures made of different materials behave under a postulated earthquake event. The response spectrum is also directly applicable in structural response analysis. In engineering analysis and design, the need is to know the ground motion due to all causative sources in a region of about $300 \mathrm{~km}$ radius around a given site. However in India, engineers have been using a standard spectral shape as recommended by the code IS-1893 (2002) all over the country, modified only by a zone factor as a proxy to peak ground acceleration (PGA). Such an approach neither recognizes the seismo-tectonic details of the region nor accounts for the risk associated with the standard response spectrum. Hence, the planned design life of structures cannot be rationally regulated by the existing earthquake hazard. Clearly, underestimation of hazard leads to questionable safety margins, whereas overestimation makes the projects uneconomical. Thus, social goals suffer in either case. It is in this context that probabilistic seismic hazard analysis (PSHA) has

Keywords. Attenuation; response spectra; Peninsular India; site coefficients. 


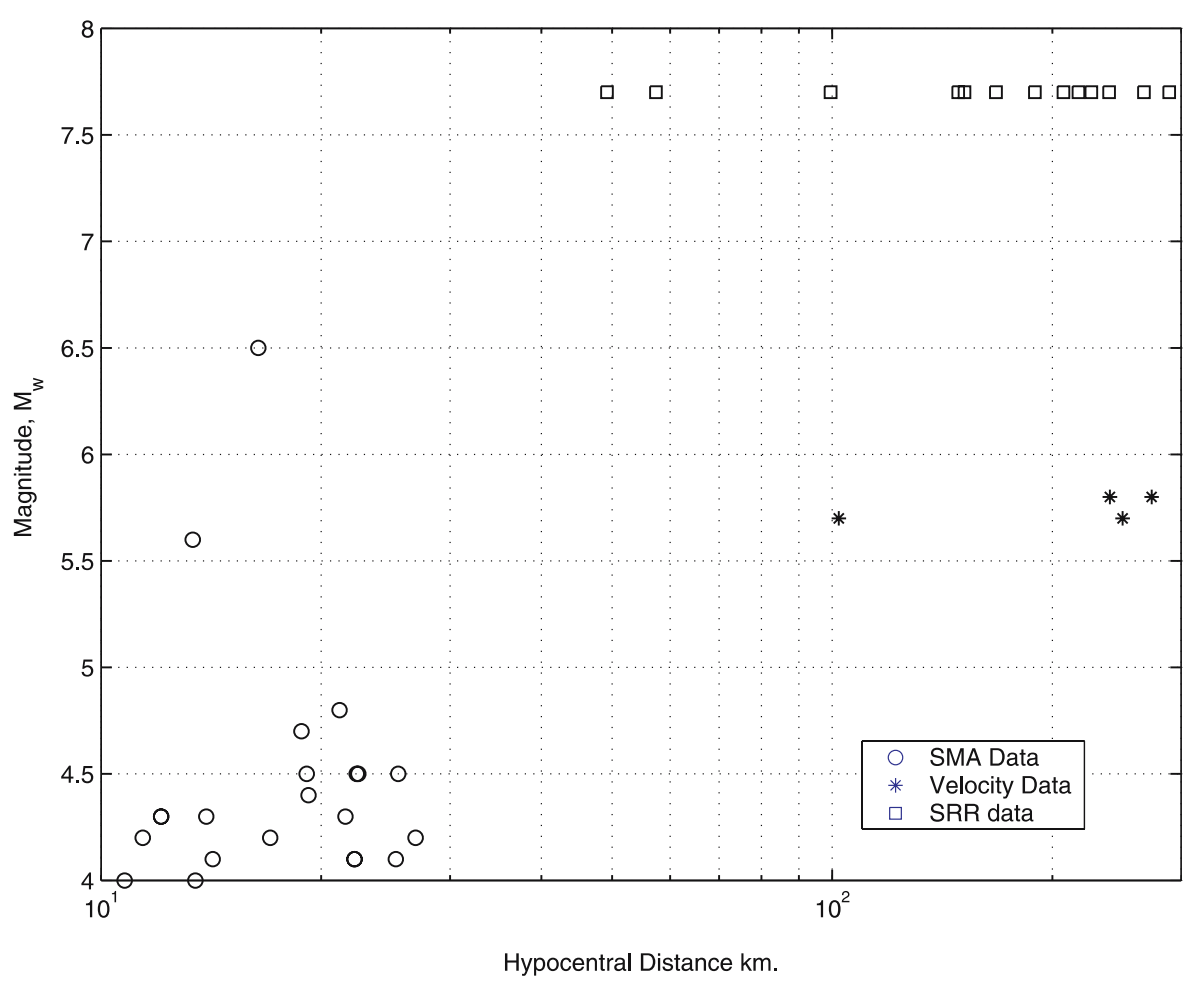

Figure 1. Available instrumental database in Peninsular India.

become indispensable when addressing engineering safety issues in terms of quantified risk levels. The expected site PGA and the response spectrum with a specified return period or risk can be derived from PSHA. Such a response spectrum, which has the same return period at all frequencies, is known as a uniform hazard response spectrum (UHRS). In order to obtain a UHRS, one has to develop regional ground motion equations relating spectral amplitudes to magnitude and distance. Due to lack of strong motion data, no equation for estimating ground motion was available for use in Peninsular India (PI). With this in view, Iyengar and Raghukanth (2004) investigated attenuation of PGA in PI through the stochastic seismological model of Boore (1983). Previously, for central and eastern United States (CEUS), where strong motion data are scarce, Boore and Atkinson (1987), Hwang and Huo (1997) have used seismological models to predict characteristics of ground motion. In the present study, this approach is applied to derive empirical equations for $5 \%$ damped response spectra, corresponding to bedrock conditions in PI. The results of the derived equation are compared with instrumental data from the Koyna earthquake $\left(M_{w}=6.5\right)$ of 11 December 1967 and the Bhuj earthquake $\left(M_{w}=7.7\right)$ of 26 January 2001. Correction factors are also found for various other sites defined in terms of the average shear wave velocity in the top 30 meters $\left(V_{30}\right)$ of the soil. This new empirical relation will be useful in prescribing design response spectra for structures in PI.

\section{Seismological model}

A critical review of the available strong motion data in PI has been presented previously by Iyengar and Raghukanth (2004). Figure 1 presents the available data in PI as a function of magnitude and epicentral distance. This brings out the existing deficiency in the database of PI from the engineering point of view. Ideally, multiple strong motion accelerogram (SMA) data from the same event should be available for distances varying from zero to $300 \mathrm{~km}$. In addition, magnitude values ranging from 4 to 8 should be covered at reasonable increments. PI is similar to many other stable continental regions (SCR) of the world where data are scarce and not representative of the existing hazards. Attenuation equations in such regions have to be based on simulated ground motions instead of past recordings. The theory and application of stochastic seismological models for estimating ground motion has been discussed by Boore $(1983,2003)$. Briefly, the Fourier amplitude spectrum of ground acceleration $A(f)$ is expressed as

$$
A(f)=C S(f) D(f) P(f) F(f) .
$$

Here, $C$ is a scaling factor, $S(f)$ is the source spectral function, $D(f)$ is the diminution function 


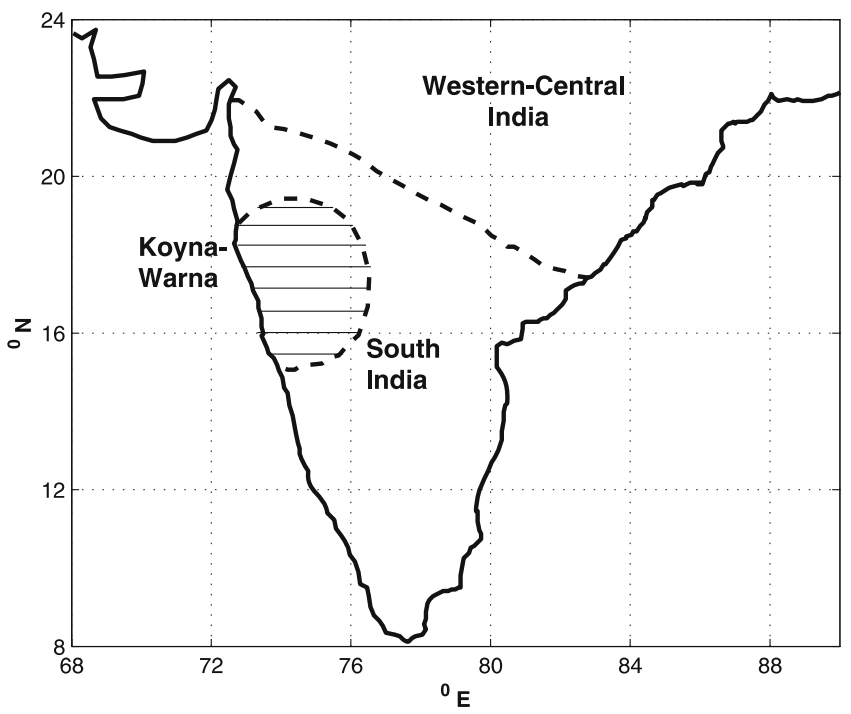

Figure 2. Three sub-regions of Peninsular India with known Q-factor.

characterizing the quality of the region, $P(f)$ is a filter to shape acceleration amplitudes beyond a high cut-off frequency $f_{m}$, and $F(f)$ is the site amplification function. In the present study, for the source, the single corner frequency model

$$
S(f)=(2 \pi f)^{2} \frac{M_{0}}{\left[1+\left(f / f_{c}\right)^{2}\right]}
$$

of Brune (1970) is used, where the corner frequency $f_{c}$, the seismic moment $M_{0}$ and the stress drop $\Delta \sigma$ are related through

$$
f_{c}=4.9 \times 10^{6} V_{s}\left(\frac{\Delta \sigma}{M_{0}}\right)^{\frac{1}{3}} .
$$

Here the shear wave velocity $V_{s}$ in the source region, corresponding to bedrock conditions, is taken as $3.6 \mathrm{~km} / \mathrm{s}$. The diminution function $D(f)$ is defined as

$$
D(f)=G \exp \left[\frac{-\pi f r}{V_{s} Q(f)}\right]
$$

in which $G$ refers to the geometric attenuation and the remaining term denotes anelastic attenuation. $r$ is the hypocentral distance and $Q$ is the quality factor of the region. The high-cut filter in the seismological model is given by

$$
P\left(f, f_{m}\right)=\left[1+\left(\frac{f}{f_{m}}\right)^{8}\right]^{-\frac{1}{2}}
$$

Here, $f_{m}$ controls the high frequency fall-off of the spectrum. The scaling factor $C$ is

$$
C=\frac{\left\langle R_{\theta \phi}\right\rangle \sqrt{2}}{4 \pi \rho V_{s}^{3}},
$$

where $\left\langle R_{\theta \phi}\right\rangle$ is the radiation coefficient averaged over an appropriate range of azimuths and takeoff angles and $\rho$ is the density of the crust at the focal depth. The coefficient $\sqrt{ } 2$ in the above equation arises as the product of the free surface amplification and partitioning of energy in orthogonal directions. Following the work of Singh et al (1999), the geometrical attenuation term $G$, for the Indian shield region, is taken to be equal to $1 / r$ for $r<100 \mathrm{~km}$ and equal to $1 /(10 \sqrt{ } r)$ for $r>100 \mathrm{~km}$. PI can be broadly divided into three regions, as far as the quality factor $Q$ is concerned (Iyengar and Raghukanth 2004). Mandal and Rastogi (1998) have found $Q$ for the Koyna-Warna $(\mathrm{K}-\mathrm{W})$ region to be $169 f^{0.77}$. For the southern India (SI) region $Q$ is $460 f^{0.83}$ and for the Western-Central (WC) region $Q$ is reported to be $508 f^{0.48}$ (Singh et al 1999). These three regions, which make up PI are shown in figure 2. The seismological model is implemented in the time domain in each region through computer simulation, consisting of three steps (Boore 1983, 2003). First, a Gaussian stationary white noise sample of length equal to the strong motion duration (Boore and Atkinson 1987),

$$
T=\frac{1}{f_{c}}+0.05 r
$$

is simulated. Second, this sample is multiplied by the modulating function of Saragoni and Hart (1974) to introduce non-stationarity and then Fourier transformed into the frequency domain. This Fourier spectrum is normalized by its rootmean-square value and multiplied by the terms of equation (1), derived from the seismological model. Third, the resulting function is transformed back into the time domain, to get a sample of acceleration time history. For calculating spectral

Table 1. Ranges of epicentral distance.

\begin{tabular}{ccc}
\hline $\begin{array}{c}\text { Moment } \\
\text { magnitude }\end{array}$ & $\begin{array}{c}\text { Epicentral } \\
\text { distance } \\
\left(r_{\text {epi }} \mathrm{km}\right)\end{array}$ & $\begin{array}{c}\text { Number of } \\
\text { distance } \\
\text { samples }\end{array}$ \\
\hline 4 & $1-300$ & 20 \\
4.5 & $1-300$ & 20 \\
5.0 & $5-300$ & 14 \\
5.5 & $15-300$ & 10 \\
6.0 & $25-300$ & 9 \\
6.5 & $35-300$ & 8 \\
7.0 & $40-300$ & 7 \\
7.5 & $45-300$ & 7 \\
8.0 & $60-300$ & 6 \\
\hline
\end{tabular}


Table 2(a). Coefficients of attenuation equation, Koyna-Warna $(K-W)$ region.

\begin{tabular}{cccccc}
\hline Period $(\mathrm{s})$ & $c_{1}$ & $c_{2}$ & $c_{3}$ & $c_{4}$ & $\sigma\left(\ln \varepsilon_{b r}\right)$ \\
\hline 0.000 & 1.7615 & 0.9325 & -0.0706 & 0.0086 & 0.3292 \\
0.010 & 1.8163 & 0.9313 & -0.0698 & 0.0087 & 0.3322 \\
0.015 & 1.9414 & 0.9249 & -0.0674 & 0.0090 & 0.3491 \\
0.020 & 2.1897 & 0.9148 & -0.0634 & 0.0094 & 0.3925 \\
0.030 & 2.7216 & 0.9030 & -0.0583 & 0.0099 & 0.4143 \\
0.040 & 2.8862 & 0.9053 & -0.0587 & 0.0097 & 0.3391 \\
0.050 & 2.8514 & 0.9127 & -0.0611 & 0.0093 & 0.3061 \\
0.060 & 2.7665 & 0.9215 & -0.0643 & 0.0089 & 0.2976 \\
0.075 & 2.6372 & 0.9356 & -0.0699 & 0.0085 & 0.2917 \\
0.090 & 2.5227 & 0.9505 & -0.0763 & 0.0082 & 0.2873 \\
0.100 & 2.4556 & 0.9608 & -0.0809 & 0.0080 & 0.2845 \\
0.150 & 2.1864 & 1.0152 & -0.1064 & 0.0072 & 0.2737 \\
0.200 & 1.9852 & 1.0723 & -0.1337 & 0.0067 & 0.2666 \\
0.300 & 1.6781 & 1.1848 & -0.1853 & 0.0059 & 0.2586 \\
0.400 & 1.4334 & 1.2880 & -0.2278 & 0.0054 & 0.2531 \\
0.500 & 1.2230 & 1.3797 & -0.2604 & 0.0050 & 0.2470 \\
0.600 & 1.0331 & 1.4603 & -0.2845 & 0.0048 & 0.2407 \\
0.700 & 0.8597 & 1.5314 & -0.3020 & 0.0045 & 0.2346 \\
0.750 & 0.7784 & 1.5638 & -0.3088 & 0.0044 & 0.2318 \\
0.800 & 0.6989 & 1.5944 & -0.3144 & 0.0043 & 0.2294 \\
0.900 & 0.5488 & 1.6505 & -0.3229 & 0.0042 & 0.2253 \\
1.000 & 0.4082 & 1.7010 & -0.3284 & 0.0041 & 0.2224 \\
1.200 & 0.1484 & 1.7880 & -0.3331 & 0.0039 & 0.2202 \\
1.500 & -0.1937 & 1.8927 & -0.3306 & 0.0037 & 0.2226 \\
2.000 & -0.6747 & 2.0218 & -0.3147 & 0.0035 & 0.2337 \\
2.500 & -1.0761 & 2.1156 & -0.2938 & 0.0034 & 0.2458 \\
3.000 & -1.4190 & 2.1869 & -0.2723 & 0.0033 & 0.2557 \\
4.000 & -1.9856 & 2.2879 & -0.2328 & 0.0033 & 0.2685 \\
\hline & & & & &
\end{tabular}

accelerations $S_{a}$, the generated acceleration time history is passed through a single degree-offreedom oscillator with damping coefficient equal to 0.05 . This way an ensemble of acceleration time histories and corresponding response spectra are obtained. The acceleration samples are conditioned on a given set of model parameters, which are by themselves uncertain. Thus the generated samples will not still reflect all the variability observed in real ground motion. To account for this, important model parameters, namely stress drop, focal depth $(h), f_{m}$ and the radiation coefficient, are treated as uniformly distributed random variables. The stress drop is taken to vary between 100 and 300 bars (Singh et al 1999). The focal depth is taken as a uniform random variable in the range 5-15 km. Based on limited past strong motion data recorded at Koyna (Krishna et al 1969) and at Khillari (Baumbach et al 1994), the cut-off frequency is taken in the interval 20-25 Hz. Following Boore and Boatwright (1984), the $\mathrm{S}$-wave radiation coefficient is taken in the interval 0.48-0.64. Spectral acceleration values are simulated for moment magnitude $\left(M_{w}\right)$ ranging from 4 to 8 in increments of 0.5 units. The distance parameter is varied in intervals of $\log _{10}\left(r_{\text {epi }}\right)=0.13$, where $r_{\text {epi }}$ stands for the epicentral distance. The combinations of $M_{w}$ and $r_{\text {epi }}$ are presented in table 1 . A lower limit on the epicentral distance has to be imposed since the present model is based on point source assumption. The number of distance samples considered for each magnitude is also shown in table 1. In all, there are 101 pairs of magnitudes and distances. For each magnitude, 100 samples of seismic parameters are used. Thus, the database consists of 10 , $100 S_{a}$ samples from 900 simulated earthquakes. Spectral acceleration values are computed for 27 natural periods presented in table 2 . This synthetic database is generated separately for $\mathrm{K}-\mathrm{W}, \mathrm{W}-\mathrm{C}$ and SI regions of PI using their respective quality factors.

\section{Ground motion equations}

Attenuation of $S_{a}$ with respect to magnitude and distance is central to hazard analysis. The attenuation equation chosen for PI is similar in form to 
Table 2(b). Coefficients of attenuation equation, southern India (SI) region.

\begin{tabular}{cccccc}
\hline Period(s) & $c_{1}$ & $c_{2}$ & $c_{3}$ & $c_{4}$ & $\sigma\left(\ln \varepsilon_{b r}\right)$ \\
\hline 0.000 & 1.7816 & 0.9205 & -0.0673 & 0.0035 & 0.3136 \\
0.010 & 1.8375 & 0.9196 & -0.0666 & 0.0035 & 0.3172 \\
0.015 & 1.9657 & 0.9136 & -0.0643 & 0.0036 & 0.3383 \\
0.020 & 2.2153 & 0.9054 & -0.0607 & 0.0037 & 0.3920 \\
0.030 & 2.7418 & 0.8988 & -0.0570 & 0.0037 & 0.3171 \\
0.040 & 2.9025 & 0.9034 & -0.0578 & 0.0036 & 0.3344 \\
0.050 & 2.8652 & 0.9113 & -0.0604 & 0.0035 & 0.300 \\
0.060 & 2.7795 & 0.9202 & -0.0637 & 0.0034 & 0.2917 \\
0.075 & 2.6483 & 0.9343 & -0.0693 & 0.0032 & 0.2865 \\
0.090 & 2.5333 & 0.9492 & -0.0757 & 0.0031 & 0.2825 \\
0.100 & 2.4651 & 0.9595 & -0.0803 & 0.0030 & 0.2801 \\
0.150 & .1941 & 1.0139 & -0.1058 & 0.0027 & 0.2703 \\
0.200 & 1.9917 & 1.0708 & -0.1331 & 0.0025 & 0.2637 \\
0.300 & 1.6832 & 1.1830 & -0.1846 & 0.0021 & 0.2563 \\
0.400 & 1.4379 & 1.2859 & -0.2269 & 0.0019 & 0.2510 \\
0.500 & 1.2262 & 1.3770 & -0.2592 & 0.0017 & 0.2450 \\
0.600 & 1.0361 & 1.4571 & -0.2830 & 0.0015 & 0.2386 \\
0.700 & 0.8621 & 1.5276 & -0.3001 & 0.0014 & 0.2323 \\
0.750 & 0.7800 & 1.5598 & -0.3067 & 0.0013 & 0.2290 \\
0.800 & 0.7008 & 1.5900 & -0.3121 & 0.0013 & 0.2268 \\
0.900 & 0.5501 & 1.6456 & -0.3203 & 0.0012 & 0.2225 \\
1.000 & 0.4087 & 1.6955 & -0.3255 & 0.0012 & 0.2194 \\
1.200 & 0.1489 & 1.7814 & -0.3298 & 0.0011 & 0.2163 \\
1.500 & -0.1943 & 1.8847 & -0.3268 & 0.0010 & 0.2175 \\
2.000 & -0.6755 & 2.0119 & -0.3105 & 0.0001 & 0.2265 \\
2.500 & -1.0762 & 2.1041 & -0.2895 & 0.0010 & 0.2365 \\
3.000 & -1.4191 & 2.1741 & -0.2680 & 0.0010 & 0.2447 \\
4.000 & -1.9847 & 2.2730 & -0.2287 & 0.0011 & 0.2544 \\
\hline & & & & &
\end{tabular}

the one used in the literature for other intra-plate regions (Atkinson and Boore 1995). The attenuation equation is of the form

$$
\begin{aligned}
\ln \left(y_{b r}\right)= & c_{1}+c_{2}(M-6)+c_{3}(M-6)^{2} \\
& -\ln (r)-c_{4} r+\ln \left(\varepsilon_{b r}\right) .
\end{aligned}
$$

In the above equation, $y_{b r}=\left(S_{a} / g\right)$ stands for the ratio of spectral acceleration at bedrock level to acceleration due to gravity. $M$ and $r$ refers to moment magnitude and hypocentral distance respectively. The coefficients of the above equation are obtained from the simulated database of $S_{a}$ by a two-step stratified regression following Joyner and Boore (1981). The average of the error term $\ln \left(\varepsilon_{b r}\right)$ is zero, but the standard deviation is of importance in probabilistic hazard analysis. The regression coefficients and the standard error $\sigma\left(\ln \varepsilon_{b r}\right)$ are reported in table $2(\mathrm{a}, \mathrm{b}, \mathrm{c})$. As an illustration, for $M_{w}=6.5$, the $5 \%$ damped response spectra on bedrock, corresponding to two hypocentral distances are shown in figure 3 . This value of $M_{w}$ is chosen as a typical design basis event possible anywhere in PI. There is considerable similarity in the shape of the response spectrum of all three regions. At large distances, attenuation is smaller at the low frequency end of the spectrum in SI. However, in the frequency range $0.2-10 \mathrm{~Hz}$, of interest in building design, the spectra are not sensitive to variation in the $Q$-factor. Hence, it would be convenient to have a single composite formula for PI. The three regions $\mathrm{K}-\mathrm{W}\left(84,950 \mathrm{~km}^{2}\right), \mathrm{W}-\mathrm{C}$ $\left(3,39,800 \mathrm{~km}^{2}\right)$ and SI $\left(4,24,750 \mathrm{~km}^{2}\right)$ cover PI in the ratio $1: 4: 5$. With this in mind, new spectral acceleration samples have been generated from the three regional populations in the above ratio to create a new synthetic database representative of PI in general. This contains 10, 100 samples as before, covering the same magnitude and distance ranges. For the chosen attenuation relation of equation (8), the parameters obtained by regression along with the standard error, for PI are reported in table 3. The above results are valid at the bedrock level, with $V_{s}$ nearly equal to $3.6 \mathrm{~km} / \mathrm{s}$. For other site conditions, they have to be modified as follows. 
$S T G$ Raghu Kanth and $R N$ Iyengar

Table 2(c). Coefficients of attenuation equation, western-central $(W-C)$ region.

\begin{tabular}{cccccc}
\hline Period(s) & $c_{1}$ & $c_{2}$ & $c_{3}$ & $c_{4}$ & $\sigma\left(\ln \varepsilon_{b r}\right)$ \\
\hline 0.000 & 1.7236 & 0.9453 & -0.0725 & 0.0064 & 0.3439 \\
0.010 & 1.8063 & 0.9379 & -0.0725 & 0.0062 & 0.3405 \\
0.015 & 1.9263 & 0.9320 & -0.0703 & 0.0066 & 0.3572 \\
0.020 & 2.1696 & 0.9224 & -0.0663 & 0.0072 & 0.3977 \\
0.030 & 2.7092 & 0.9087 & -0.0602 & 0.0081 & 0.4152 \\
0.040 & 2.8823 & 0.9090 & -0.0597 & 0.0078 & 0.3422 \\
0.050 & 2.8509 & 0.9153 & -0.0617 & 0.0073 & 0.3087 \\
0.060 & 2.7684 & 0.9235 & -0.0648 & 0.0067 & 0.2988 \\
0.075 & 2.6403 & 0.9372 & -0.0703 & 0.0061 & 0.2919 \\
0.090 & 2.5270 & 0.9518 & -0.0766 & 0.0056 & 0.2868 \\
0.100 & 2.4597 & 0.9620 & -0.0811 & 0.0053 & 0.2839 \\
0.150 & 2.1912 & 1.0160 & -0.1065 & 0.0043 & 0.2726 \\
0.200 & 1.9900 & 1.0728 & -0.1338 & 0.0037 & 0.2654 \\
0.300 & 1.6827 & 1.1852 & -0.1854 & 0.0029 & 0.2575 \\
0.400 & 1.4382 & 1.2883 & -0.2279 & 0.0023 & 0.2520 \\
0.500 & 1.2271 & 1.3799 & -0.2606 & 0.0019 & 0.2461 \\
0.600 & 1.0376 & 1.4605 & -0.2848 & 0.0017 & 0.2398 \\
0.700 & 0.8639 & 1.5316 & -0.3023 & 0.0015 & 0.2337 \\
0.750 & 0.7821 & 1.5639 & -0.3090 & 0.0014 & 0.2310 \\
0.800 & 0.7031 & 1.5945 & -0.3147 & 0.0013 & 0.2285 \\
0.900 & 0.5527 & 1.6506 & -0.3231 & 0.0011 & 0.2244 \\
1.000 & 0.4115 & 1.7010 & -0.3287 & 0.0010 & 0.2215 \\
1.200 & 0.1521 & 1.7878 & -0.3334 & 0.0009 & 0.2191 \\
1.500 & -0.1909 & 1.8922 & -0.3308 & 0.0007 & 0.2214 \\
2.000 & -0.6722 & 2.0209 & -0.3148 & 0.0006 & 0.2321 \\
2.500 & -1.0731 & 2.1142 & -0.2939 & 0.0006 & 0.2437 \\
3.000 & -1.4164 & 2.1850 & -0.2724 & 0.0006 & 0.2531 \\
4.000 & -1.9828 & 2.2851 & -0.2329 & 0.0006 & 0.2649 \\
\hline & & & & &
\end{tabular}

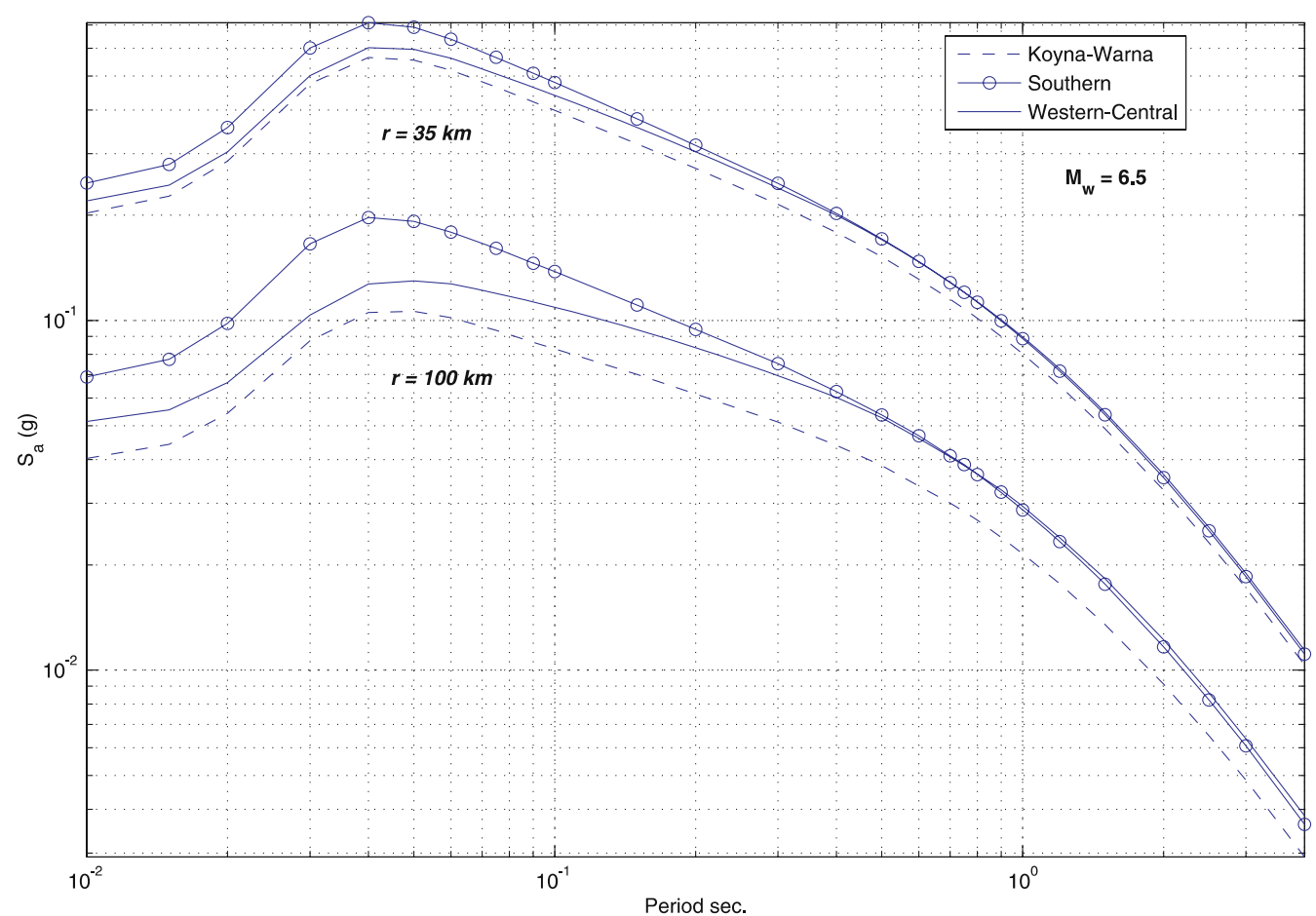

Figure 3. Response spectra for the three sub-regions of PI of figure 2. 
Table 3. Coefficients of attenuation equation, Peninsular India.

\begin{tabular}{lccccc}
\hline Period(s) & $c_{1}$ & $c_{2}$ & $c_{3}$ & $c_{4}$ & $\sigma\left(\varepsilon_{b r}\right)$ \\
\hline 0.000 & 1.6858 & 0.9241 & -0.0760 & 0.0057 & 0.4648 \\
0.010 & 1.7510 & 0.9203 & -0.0748 & 0.0056 & 0.4636 \\
0.015 & 1.8602 & 0.9184 & -0.0666 & 0.0053 & 0.4230 \\
0.020 & 2.0999 & 0.9098 & -0.0630 & 0.0056 & 0.4758 \\
0.030 & 2.6310 & 0.8999 & -0.0582 & 0.0060 & 0.5189 \\
0.040 & 2.8084 & 0.9022 & -0.0583 & 0.0059 & 0.4567 \\
0.050 & 2.7800 & 0.9090 & -0.0605 & 0.0055 & 0.4130 \\
0.060 & 2.6986 & 0.9173 & -0.0634 & 0.0052 & 0.4201 \\
0.075 & 2.5703 & 0.9308 & -0.0687 & 0.0049 & 0.4305 \\
0.090 & 2.4565 & 0.9450 & -0.0748 & 0.0046 & 0.4572 \\
0.100 & 2.3890 & 0.9548 & -0.0791 & 0.0044 & 0.4503 \\
0.150 & 2.1200 & 1.0070 & -0.1034 & 0.0038 & 0.4268 \\
0.200 & 1.9192 & 1.0619 & -0.1296 & 0.0034 & 0.3932 \\
0.300 & 1.6138 & 1.1708 & -0.1799 & 0.0028 & 0.3984 \\
0.400 & 1.3720 & 1.2716 & -0.2219 & 0.0024 & 0.3894 \\
0.500 & 1.1638 & 1.3615 & -0.2546 & 0.0021 & 0.3817 \\
0.600 & 0.9770 & 1.4409 & -0.2791 & 0.0019 & 0.3744 \\
0.700 & 0.8061 & 1.5111 & -0.2970 & 0.0017 & 0.3676 \\
0.750 & 0.7254 & 1.5432 & -0.3040 & 0.0016 & 0.3645 \\
0.800 & 0.6476 & 1.5734 & -0.3099 & 0.0016 & 0.3616 \\
0.900 & 0.4996 & 1.6291 & -0.3188 & 0.0015 & 0.3568 \\
1.000 & 0.3604 & 1.6791 & -0.3248 & 0.0014 & 0.3531 \\
1.200 & 0.2904 & 1.7464 & -0.3300 & 0.0013 & 0.3748 \\
1.500 & -0.2339 & 1.8695 & -0.3290 & 0.0011 & 0.3479 \\
2.000 & -0.7096 & 1.9983 & -0.3144 & 0.0011 & 0.3140 \\
2.500 & -1.1064 & 2.0919 & -0.2945 & 0.0010 & 0.3222 \\
3.000 & -1.4468 & 2.1632 & -0.2737 & 0.0011 & 0.3493 \\
4.000 & -2.0090 & 2.2644 & -0.2350 & 0.0011 & 0.3182 \\
\hline & & & & &
\end{tabular}

Table 4(a). Random sample profile. A-type site.

\begin{tabular}{|c|c|c|c|c|c|c|c|}
\hline \multicolumn{4}{|c|}{$\mathrm{A}-1\left(V_{30}=1.5 \mathrm{~km} / \mathrm{s}\right)$} & \multicolumn{4}{|c|}{$\mathrm{A}-2\left(V_{30}=2.00 \mathrm{~km} / \mathrm{s}\right)$} \\
\hline $\begin{array}{l}\text { Th. } \\
(\mathrm{m})\end{array}$ & $\begin{array}{l}\text { Density } \\
\left(\mathrm{g} / \mathrm{cm}^{3}\right)\end{array}$ & $\begin{array}{l}\text { Shear wave } \\
\text { vel. }(\mathrm{km} / \mathrm{s})\end{array}$ & Q & $\begin{array}{l}\text { Th. } \\
(\mathrm{m})\end{array}$ & $\begin{array}{l}\text { Density } \\
\left(\mathrm{g} / \mathrm{cm}^{3}\right)\end{array}$ & $\begin{array}{l}\text { Shear wave } \\
\text { vel. }(\mathrm{km} / \mathrm{s})\end{array}$ & Q \\
\hline 500 & 2.4 & 1.50 & 50 & 1000 & 2.1 & 2.00 & 100 \\
\hline 1500 & 2.5 & 2.00 & 500 & 4000 & 2.4 & 2.20 & 500 \\
\hline 500 & 2.5 & 2.30 & 2000 & 5000 & 2.5 & 3.10 & 2000 \\
\hline 9000 & 2.6 & 2.95 & 1500 & 4000 & 2.9 & 3.20 & 1000 \\
\hline 10000 & 2.6 & 3.00 & 1000 & & & & \\
\hline \multicolumn{4}{|c|}{ Bedrock } & \multicolumn{4}{|c|}{ Bedrock } \\
\hline
\end{tabular}

\section{Site correction coefficients}

The surface level ground motion at a given site may be visualized as the bedrock motion modified by soil layers. The local site property is expressed in terms of the average shear wave velocity in the top 30 meters of the soil. This is the recognized NEHRP (BSSC 2001) approach, wherein sites are classified as A: $\left(V_{30}>1.5 \mathrm{~km} / \mathrm{s}\right) ;$ B: $\left(0.76 \mathrm{~km} / \mathrm{s}<V_{30} \leq 1.5 \mathrm{~km} / \mathrm{s}\right)$; C: $\left(0.36 \mathrm{~km} / \mathrm{s}<V_{30} \leq 0.76 \mathrm{~km} / \mathrm{s}\right) ; \quad$ D: $(0.18 \mathrm{~km} / \mathrm{s}$ $\left.<V_{30} \leq 0.36 \mathrm{~km} / \mathrm{s}\right)$. E- and F-type sites with $V_{30} \leq 0.18 \mathrm{~km} / \mathrm{s}$ are susceptible for liquefaction and failure. The general approach of spectral attenuation described above can be extended to A, B, C and D-type sites with the help of soil profiles and 
Table 4(b). Random sample profile. B-type site.

\begin{tabular}{cccc|cccc}
\hline & \multicolumn{2}{c|}{$\mathrm{B}-1\left(V_{30}=1.01 \mathrm{~km} / \mathrm{s}\right)$} & \multicolumn{3}{c}{$\mathrm{B}-2\left(V_{30}=0.89 \mathrm{~km} / \mathrm{s}\right)$} \\
\hline Mtl. & $\begin{array}{l}\text { Th. } \\
(\mathrm{m})\end{array}$ & $\begin{array}{c}\text { Density } \\
\left(\mathrm{g} / \mathrm{cm}^{3}\right)\end{array}$ & $\begin{array}{l}\text { Shear wave } \\
\text { vel. }(\mathrm{km} / \mathrm{s})\end{array}$ & $\mathrm{Mtl}$. & $\begin{array}{l}\text { Th. } \\
(\mathrm{m})\end{array}$ & $\begin{array}{c}\text { Density } \\
\left(\mathrm{g} / \mathrm{cm}^{3}\right)\end{array}$ & $\begin{array}{c}\text { Shear wave } \\
\text { vel. }(\mathrm{km} / \mathrm{s})\end{array}$ \\
\hline $\mathrm{C}$ & 10.0 & 2.11 & 0.68 & $\mathrm{C}$ & 8.0 & 2.10 & 0.65 \\
$\mathrm{C}$ & 5.0 & 2.12 & 0.97 & $\mathrm{R}$ & 6.0 & 2.11 & 0.76 \\
$\mathrm{R}$ & 5.0 & 2.12 & 1.10 & $\mathrm{R}$ & 6.0 & 2.12 & 0.90 \\
$\mathrm{R}$ & 8.0 & 2.10 & 1.30 & $\mathrm{R}$ & 8.0 & 2.15 & 1.13 \\
$\mathrm{R}$ & 15.0 & 2.16 & 1.40 & $\mathrm{R}$ & 1.0 & 2.17 & 1.34 \\
& & $\mathrm{~A}-2$ & & & & $\mathrm{~A}-2$ & \\
\hline
\end{tabular}

Table 4(c). Random sample profile. C-type site.

\begin{tabular}{|c|c|c|c|c|c|c|c|}
\hline \multicolumn{4}{|c|}{$\mathrm{C}-1\left(V_{30}=0.39 \mathrm{~km} / \mathrm{s}\right)$} & \multicolumn{4}{|c|}{$\mathrm{C}-2\left(V_{30}=0.38 \mathrm{~km} / \mathrm{s}\right)$} \\
\hline Mtl. & $\begin{array}{l}\text { Th. } \\
\text { (m) }\end{array}$ & $\begin{array}{l}\text { Density } \\
\left(\mathrm{g} / \mathrm{cm}^{3}\right)\end{array}$ & $\begin{array}{l}\text { Shear wave } \\
\text { vel. }(\mathrm{km} / \mathrm{s})\end{array}$ & Mtl. & $\begin{array}{l}\text { Th. } \\
\text { (m) }\end{array}$ & $\begin{array}{l}\text { Density } \\
\left(\mathrm{g} / \mathrm{cm}^{3}\right)\end{array}$ & $\begin{array}{l}\text { Shear wave } \\
\text { vel. }(\mathrm{km} / \mathrm{s})\end{array}$ \\
\hline $\mathrm{C}$ & 1.5 & 2.01 & 0.24 & $\mathrm{C}$ & 3.2 & 2.02 & 0.32 \\
\hline $\mathrm{C}$ & 4.0 & 2.02 & 0.36 & $\mathrm{C}$ & 4.5 & 2.05 & 0.36 \\
\hline S & 10.0 & 2.12 & 0.39 & $\mathrm{C}$ & 10.2 & 2.07 & 0.41 \\
\hline S & 11.2 & 2.10 & 0.41 & $\mathrm{C}$ & 5.6 & 2.11 & 0.46 \\
\hline S & 9.3 & 2.06 & 0.39 & S & 15.4 & 2.01 & 0.31 \\
\hline $\mathrm{S}$ & 5.6 & 2.08 & 0.47 & S & 18.4 & 2.12 & 0.29 \\
\hline $\mathrm{C}$ & 10.9 & 2.16 & 0.56 & $\mathrm{C}$ & 7.4 & 2.13 & 0.36 \\
\hline $\mathrm{C}$ & 7.3 & 2.13 & 0.66 & $\mathrm{C}$ & 10.4 & 2.01 & 0.59 \\
\hline $\mathrm{C}$ & 15.1 & 2.21 & 0.48 & $\mathrm{C}$ & 14.3 & 2.16 & 0.58 \\
\hline $\mathrm{C}$ & 25.1 & 2.14 & 0.56 & $\mathrm{C}$ & 10.5 & 2.12 & 0.54 \\
\hline $\mathrm{R}$ & 10.0 & 2.11 & 0.74 & $\mathrm{R}$ & 10.0 & 2.11 & 0.74 \\
\hline $\mathrm{R}$ & 8.0 & 2.12 & 0.60 & $\mathrm{R}$ & 8.0 & 2.12 & 0.60 \\
\hline $\mathrm{R}$ & 11.0 & 2.11 & 0.98 & $\mathrm{R}$ & 11.0 & 2.11 & 0.98 \\
\hline $\mathrm{R}$ & 5.0 & 2.14 & 1.10 & $\mathrm{R}$ & 5.0 & 2.14 & 1.10 \\
\hline \multirow[t]{2}{*}{$\mathrm{R}$} & 16.0 & 2.12 & 1.20 & $\mathrm{R}$ & 16.0 & 2.12 & 1.20 \\
\hline & & A-2 & & & & A-2 & \\
\hline
\end{tabular}

Table 4(d). Random sample profile. D-type site.

\begin{tabular}{crcc|rrrc}
\hline & \multicolumn{2}{c|}{$\mathrm{D}-1\left(V_{30}=0.27 \mathrm{~km} / \mathrm{s}\right)$} & \multicolumn{3}{c}{$\mathrm{D}-2\left(V_{30}=0.26 \mathrm{~km} / \mathrm{s}\right)$} \\
\hline & $\mathrm{Th}$. & $\begin{array}{c}\text { Density } \\
\left(\mathrm{g} / \mathrm{cm}^{3}\right)\end{array}$ & $\begin{array}{c}\text { Shear wave } \\
\text { vel. }(\mathrm{km} / \mathrm{s})\end{array}$ & $\mathrm{Mtl}$. & $\begin{array}{r}\text { Th. } \\
(\mathrm{m})\end{array}$ & $\begin{array}{c}\text { Density } \\
\left(\mathrm{g} / \mathrm{cm}^{3}\right)\end{array}$ & $\begin{array}{c}\text { Shear wave } \\
\text { vel. }(\mathrm{km} / \mathrm{s})\end{array}$ \\
\hline $\mathrm{S}$ & 3.7 & 1.76 & 0.16 & $\mathrm{C}$ & 3.2 & 1.65 & 0.13 \\
$\mathrm{C}$ & 2.8 & 2.08 & 0.41 & $\mathrm{~S}$ & 4.5 & 1.82 & 0.18 \\
$\mathrm{~S}$ & 6.4 & 2.16 & 0.24 & $\mathrm{~S}$ & 10.2 & 2.01 & 0.24 \\
$\mathrm{~S}$ & 3.7 & 2.01 & 0.23 & $\mathrm{C}$ & 5.6 & 2.11 & 0.33 \\
$\mathrm{~S}$ & 18.6 & 2.01 & 0.30 & $\mathrm{C}$ & 15.4 & 2.01 & 0.34 \\
$\mathrm{C}$ & 9.2 & 2.08 & 0.35 & $\mathrm{C}$ & 18.4 & 2.00 & 0.35 \\
$\mathrm{C}$ & 10.9 & 2.16 & 0.36 & $\mathrm{C}$ & 7.4 & 2.10 & 0.38 \\
$\mathrm{C}$ & 7.3 & 2.08 & 0.58 & $\mathrm{C}$ & 10.4 & 2.14 & 0.49 \\
$\mathrm{C}$ & 6.1 & 2.01 & 0.40 & $\mathrm{C}$ & 14.3 & 2.16 & 0.52 \\
$\mathrm{C}$ & 31.4 & 2.08 & 0.58 & $\mathrm{C}$ & 10.5 & 2.12 & 0.59 \\
$\mathrm{R}$ & 10.0 & 2.11 & 0.74 & $\mathrm{R}$ & 10.0 & 2.11 & 0.74 \\
$\mathrm{R}$ & 8.0 & 2.12 & 0.60 & $\mathrm{R}$ & 8.0 & 2.12 & 0.60 \\
$\mathrm{R}$ & 11.0 & 2.11 & 0.98 & $\mathrm{R}$ & 11.0 & 2.11 & 0.98 \\
$\mathrm{R}$ & 5.0 & 2.14 & 1.10 & $\mathrm{R}$ & 5.0 & 2.14 & 1.10 \\
$\mathrm{R}$ & 16.0 & 2.12 & 1.20 & $\mathrm{R}$ & 16.0 & 2.12 & 1.20 \\
& & $\mathrm{~A}-2$ & & & & $\mathrm{~A}-2$ & \\
\hline
\end{tabular}

C - Clay; $\mathbf{R}$ - Rock; S - Sand; Q values are included in the damping ratio curves (Idriss and Sun 1992). 

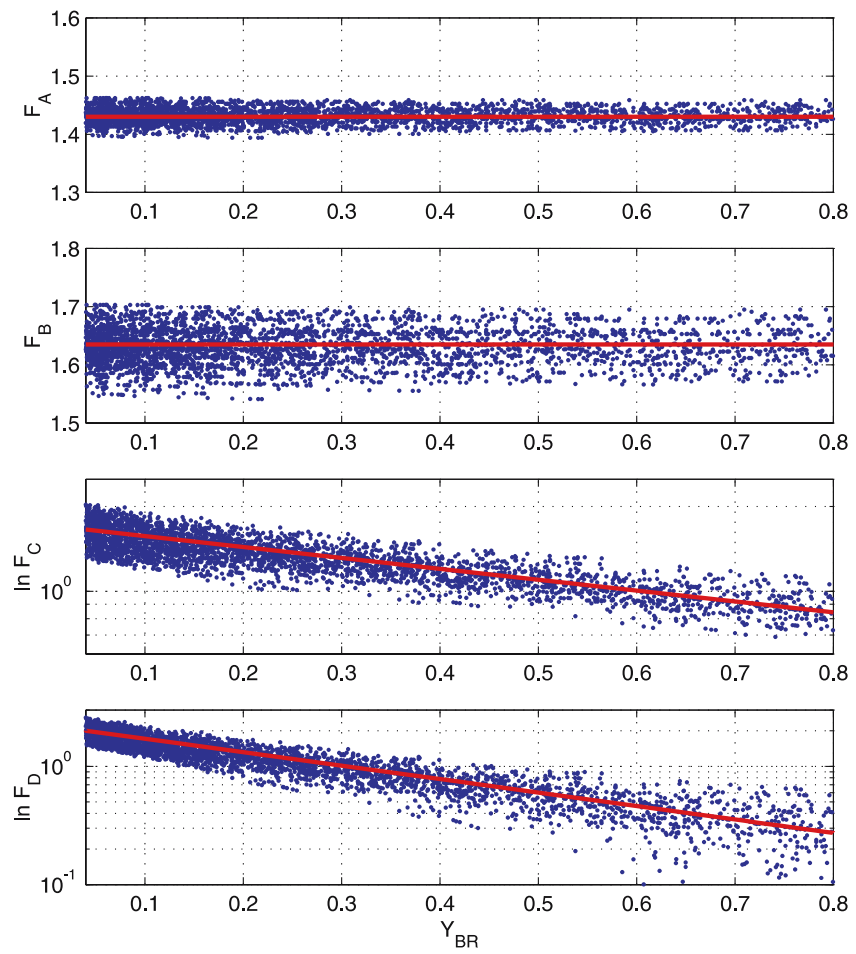

Figure 4. Variation of site coefficients for surface level PGA corresponding to zero period in $S_{a}$.

$V_{s}$ values sampled from the region. In addition to uncertainties in magnitudes and hypocentral distances, one has to consider the variations in local soil properties for estimating spectral accelerations at the ground surface. Any number of combinations can lead to the same $V_{30}$ because this is an average value. Thus, for a specific site, precise correction of the bedrock results will be possible only when the soil section data are available, including the variation of $V_{s}$ with depth. However, when one is interested in a broad region like PI and the purpose is to develop a general design response spectrum, statistical simulation is a viable alternative. A random sample of ten profiles in each site category A, B, C and D is selected for further study. These are realistic because they are drawn from actual borehole data from project sites in the country. In table 4 (a, b, c, d) a few typical samples of such profiles are presented. The details of B, C and D type soil profiles are likely to vary widely according to the region. Here it is assumed that these are lying above A-type rock layers specific to the region. Modification between bedrock and A-type sites is a linear problem in one dimension and for such sites amplification can be found directly by the quarter-wavelength method of Boore and Joyner (1997). However, for B, C and D-type profiles soil layering, viscoelastic properties and nonlinear effects are important. These can be handled with the software SHAKE91, which requires the basement rock to be of A-type. The shear modulus reduction ratio and damping ratio curves for clay, sand and rock are taken as given by Idriss and Sun (1992). Acceleration time histories are first generated for A-type rock profiles and used as input to $\mathrm{B}, \mathrm{C}$ and D-type profiles. The site coefficient $F_{s}$, $(s=\mathrm{A}, \mathrm{B}, \mathrm{C}, \mathrm{D})$ defined as the ratio of spectral acceleration at the surface to the bedrock value is determined for all the previous 27 natural periods. An important aspect of soil amplification studies is the possibility of reduction of $S_{a}$ values between the bedrock and surface due to softening of soil layers. To highlight this effect, the dependence of site coefficient is shown for $S_{a}$ at zero period with respect to the corresponding bedrock value in figure 4 . This is the ratio of the surface PGA to the bedrock value. It can be observed that $F_{\mathrm{A}}$ and $F_{\mathrm{B}}$ the site coefficients for $\mathrm{A}$ - and $\mathrm{B}$-type soils respectively are randomly scattered, indicating that these are nearly independent of the bedrock values. However, site coefficients for C- and D-type sites exhibit strong dependence on bedrock values. This relation can be empirically expressed as,

$$
\ln F_{s}=a_{1} y_{b r}+a_{2}+\ln \delta_{s},
$$

where $a_{1}$ and $a_{2}$ are the regression coefficients and $\delta_{s}$ is the error term. These coefficients along with the standard deviation of $\ln \delta_{s}$ are presented in table 5 . The site coefficient $F_{s}$ is a function of the natural period and is like a modification factor on the average $S_{a}$ value at bedrock. With the help of table 3 and equation (8), the average $5 \%$ response spectrum can be easily found for any A, B, C and D-type site in PI from the expression

$$
y_{s}=y_{b r} F_{s} .
$$

It is found numerically that the error terms $\varepsilon_{b r}$ and $\delta_{s}$ are uncorrelated. Hence, the deviation of $y_{s}$ from its mean in terms of $\varepsilon_{s}$ is characterized by the standard deviation,

$$
\sigma\left(\ln \varepsilon_{s}\right)=\sqrt{\sigma\left(\ln \varepsilon_{b r}\right)^{2}+\sigma\left(\ln \delta_{s}\right)^{2}} .
$$

As an example of using the present theory, in figure 5 the average response spectra for an event of magnitude $M_{w}=6.5$ occurring at a hypocentral distance of $35 \mathrm{~km}$ and $100 \mathrm{~km}$ are presented for four different site conditions. As the site changes from A to $\mathrm{D}$, the shift of the predominant frequency from higher to lower values is clearly indicated in this figure.

\section{Comparison with other investigations}

Toro et al (1997), Hwang et al (1997), Campbell (2003) and Atkinson and Boore (2006) have 
Table 5. Coefficients for including local site condition.

\begin{tabular}{|c|c|c|c|c|c|c|c|c|c|c|}
\hline \multirow{2}{*}{$\begin{array}{l}\text { Period } \\
\text { (s) }\end{array}$} & \multicolumn{2}{|c|}{$F_{A}\left(a_{1}=0\right)$} & \multicolumn{2}{|c|}{$F_{B}\left(a_{1}=0\right)$} & \multicolumn{3}{|c|}{$F_{C}$} & \multicolumn{3}{|c|}{$F_{D}$} \\
\hline & $a_{2}$ & $\sigma\left(\ln \delta_{s}\right)$ & $a_{2}$ & $\sigma\left(\ln \delta_{s}\right)$ & $a_{1}$ & $a_{2}$ & $\sigma\left(\ln \delta_{s}\right)$ & $a_{1}$ & $a_{2}$ & $\sigma\left(\ln \delta_{s}\right)$ \\
\hline 0.000 & 0.36 & 0.03 & 0.49 & 0.08 & -0.89 & 0.66 & 0.23 & -2.61 & 0.80 & 0.36 \\
\hline 0.010 & 0.35 & 0.04 & 0.43 & 0.11 & -0.89 & 0.66 & 0.23 & -2.62 & 0.80 & 0.37 \\
\hline 0.015 & 0.31 & 0.06 & 0.36 & 0.16 & -0.89 & 0.54 & 0.23 & -2.62 & 0.69 & 0.37 \\
\hline 0.020 & 0.26 & 0.08 & 0.24 & 0.09 & -0.91 & 0.32 & 0.19 & -2.61 & 0.55 & 0.34 \\
\hline 0.030 & 0.25 & 0.04 & 0.18 & 0.03 & -0.94 & -0.01 & 0.21 & -2.54 & 0.42 & 0.31 \\
\hline 0.040 & 0.31 & 0.01 & 0.29 & 0.01 & -0.87 & -0.05 & 0.21 & -2.44 & 0.58 & 0.31 \\
\hline 0.050 & 0.36 & 0.01 & 0.40 & 0.02 & -0.83 & 0.11 & 0.18 & -2.34 & 0.65 & 0.29 \\
\hline 0.060 & 0.39 & 0.01 & 0.48 & 0.02 & -0.83 & 0.27 & 0.18 & -2.78 & 0.83 & 0.29 \\
\hline 0.075 & 0.43 & 0.01 & 0.56 & 0.03 & -0.81 & 0.50 & 0.19 & -2.32 & 0.93 & 0.19 \\
\hline 0.090 & 0.46 & 0.01 & 0.62 & 0.02 & -0.83 & 0.68 & 0.18 & -2.27 & 1.04 & 0.29 \\
\hline 0.100 & 0.47 & 0.01 & 0.71 & 0.01 & -0.84 & 0.79 & 0.15 & -2.25 & 1.12 & 0.19 \\
\hline 0.150 & 0.50 & 0.02 & 0.74 & 0.01 & -0.93 & 1.11 & 0.16 & -2.38 & 1.40 & 0.28 \\
\hline 0.200 & 0.51 & 0.02 & 0.76 & 0.02 & -0.78 & 1.16 & 0.18 & -2.32 & 1.57 & 0.19 \\
\hline 0.300 & 0.53 & 0.03 & 0.76 & 0.02 & 0.06 & 1.03 & 0.13 & -1.86 & 1.51 & 0.16 \\
\hline 0.400 & 0.52 & 0.03 & 0.74 & 0.01 & -0.06 & 0.99 & 0.13 & -1.28 & 1.43 & 0.16 \\
\hline 0.500 & 0.51 & 0.06 & 0.72 & 0.02 & -0.17 & 0.97 & 0.12 & -0.69 & 1.34 & 0.21 \\
\hline 0.600 & 0.49 & 0.01 & 0.69 & 0.02 & -0.04 & 0.93 & 0.12 & -0.56 & 1.32 & 0.21 \\
\hline 0.700 & 0.49 & 0.01 & 0.68 & 0.02 & -0.25 & 0.88 & 0.12 & -0.42 & 1.29 & 0.21 \\
\hline 0.750 & 0.48 & 0.02 & 0.66 & 0.02 & 0.36 & 0.86 & 0.09 & -0.36 & 1.28 & 0.19 \\
\hline 0.800 & 0.47 & 0.01 & 0.63 & 0.01 & -0.34 & 0.84 & 0.12 & -0.18 & 1.27 & 0.21 \\
\hline 0.900 & 0.46 & 0.01 & 0.61 & 0.02 & -0.29 & 0.81 & 0.12 & 0.17 & 1.25 & 0.21 \\
\hline 1.000 & 0.45 & 0.02 & 0.62 & 0.11 & 0.24 & 0.78 & 0.10 & 0.53 & 1.23 & 0.15 \\
\hline 1.200 & 0.43 & 0.01 & 0.57 & 0.03 & -0.11 & 0.67 & 0.09 & 0.77 & 1.14 & 0.17 \\
\hline 1.500 & 0.39 & 0.02 & 0.51 & 0.04 & -0.10 & 0.62 & 0.09 & 1.13 & 1.01 & 0.17 \\
\hline 2.000 & 0.36 & 0.03 & 0.44 & 0.06 & -0.13 & 0.47 & 0.08 & 0.61 & 0.79 & 0.15 \\
\hline 2.500 & 0.34 & 0.04 & 0.40 & 0.08 & -0.15 & 0.39 & 0.08 & 0.37 & 0.68 & 0.15 \\
\hline 3.000 & 0.32 & 0.04 & 0.38 & 0.10 & -0.17 & 0.32 & 0.09 & 0.13 & 0.60 & 0.13 \\
\hline 4.000 & 0.31 & 0.05 & 0.36 & 0.11 & -0.19 & 0.35 & 0.08 & 0.12 & 0.44 & 0.15 \\
\hline
\end{tabular}

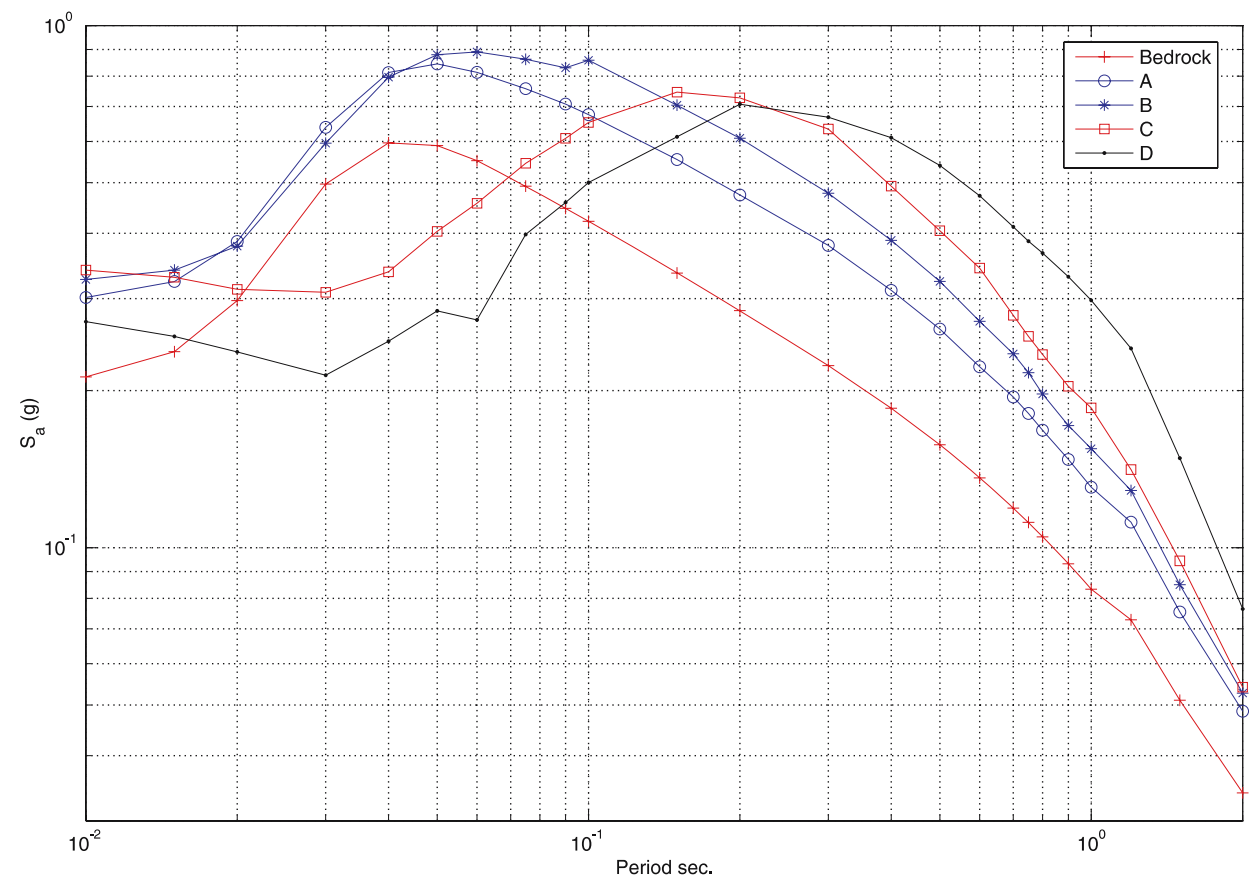

Figure 5. Effect of local site condition on response spectra in PI. $M_{w}=6.5 ; r=35 \mathrm{~km}$. 


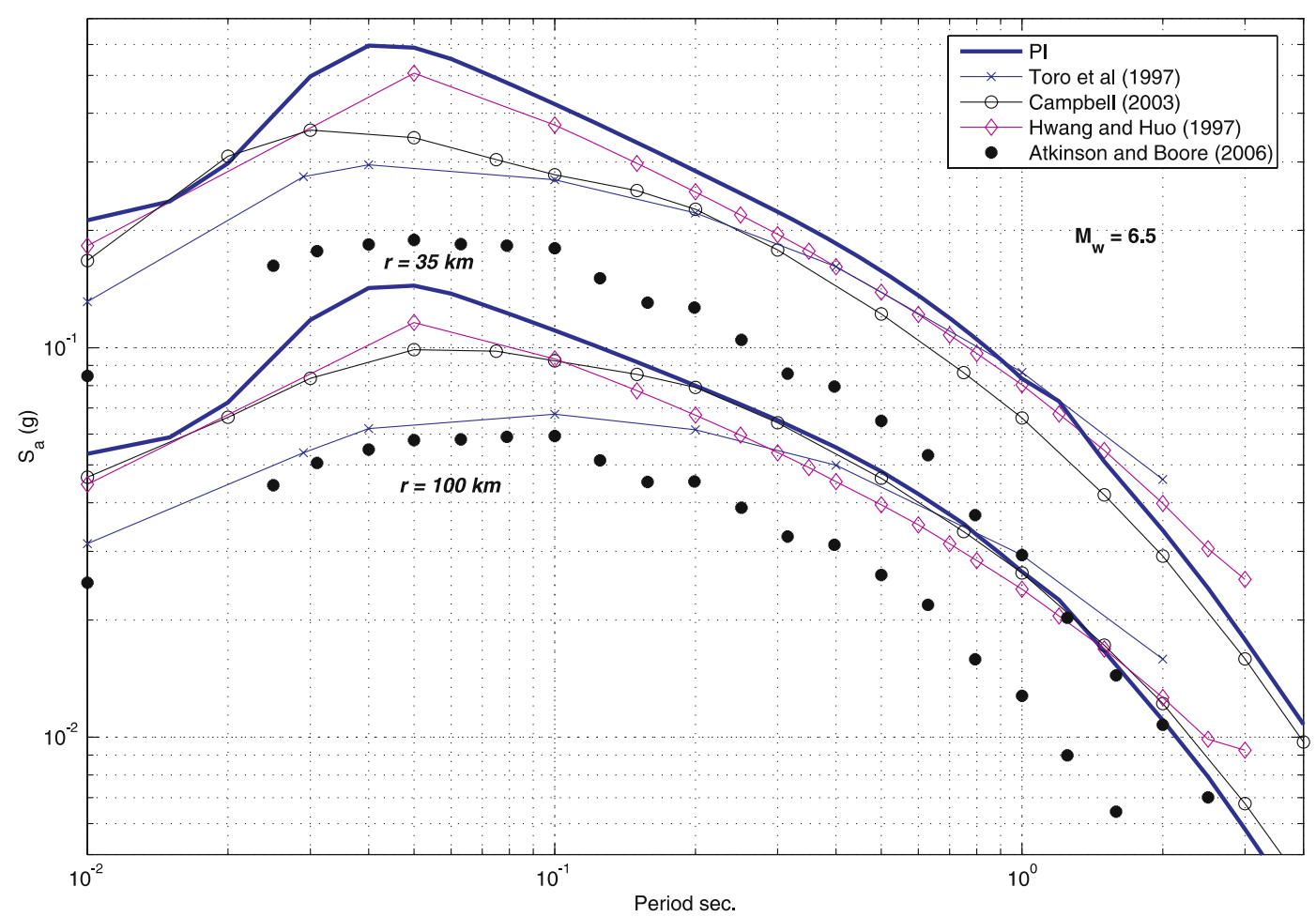

Figure 6. Comparison of PI 5\% damped response spectra with spectra estimated for eastern north America.

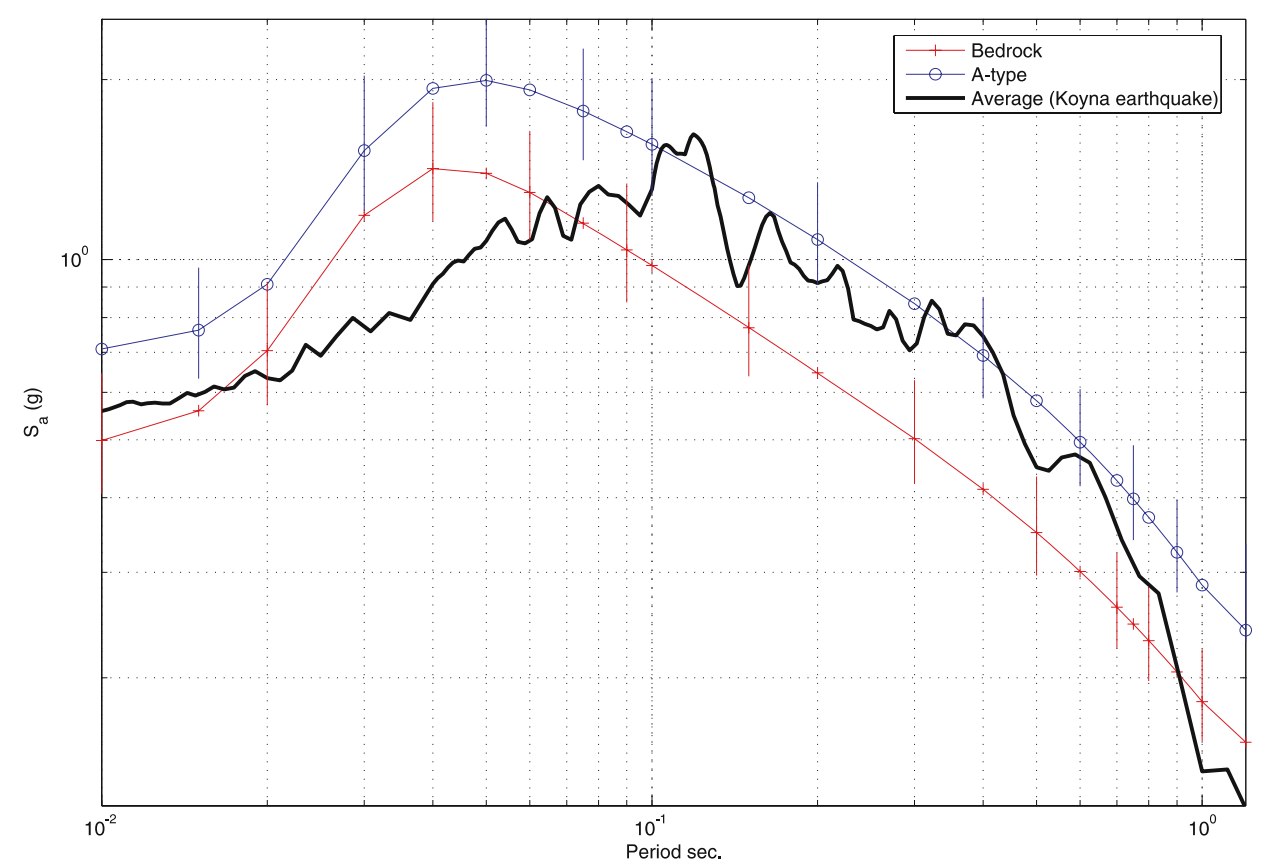

Figure 7. Comparison of estimated response spectra with recorded data of Koyna earthquake of 11 December 1967 $\left(M_{w}=6.5 ; r=16 \mathrm{~km}, \eta=5 \%\right)$. The vertical bands are 1 -sigma wide about the mean.

proposed empirical relations based on seismological models to investigate attenuation of bedrock motion in eastern north America. Among these relations, the empirical equation proposed by Atkinson and Boore (2006) is based on the stochastic finite fault model. The other three relations are based on the point source, single-corner frequency spectral model of Brune (1970) which is the same as used in this present study. In figure 6 , the PI response spectrum, for $M_{w}=6.5$ under bedrock conditions is plotted along with the results of the above authors. All the results peak 

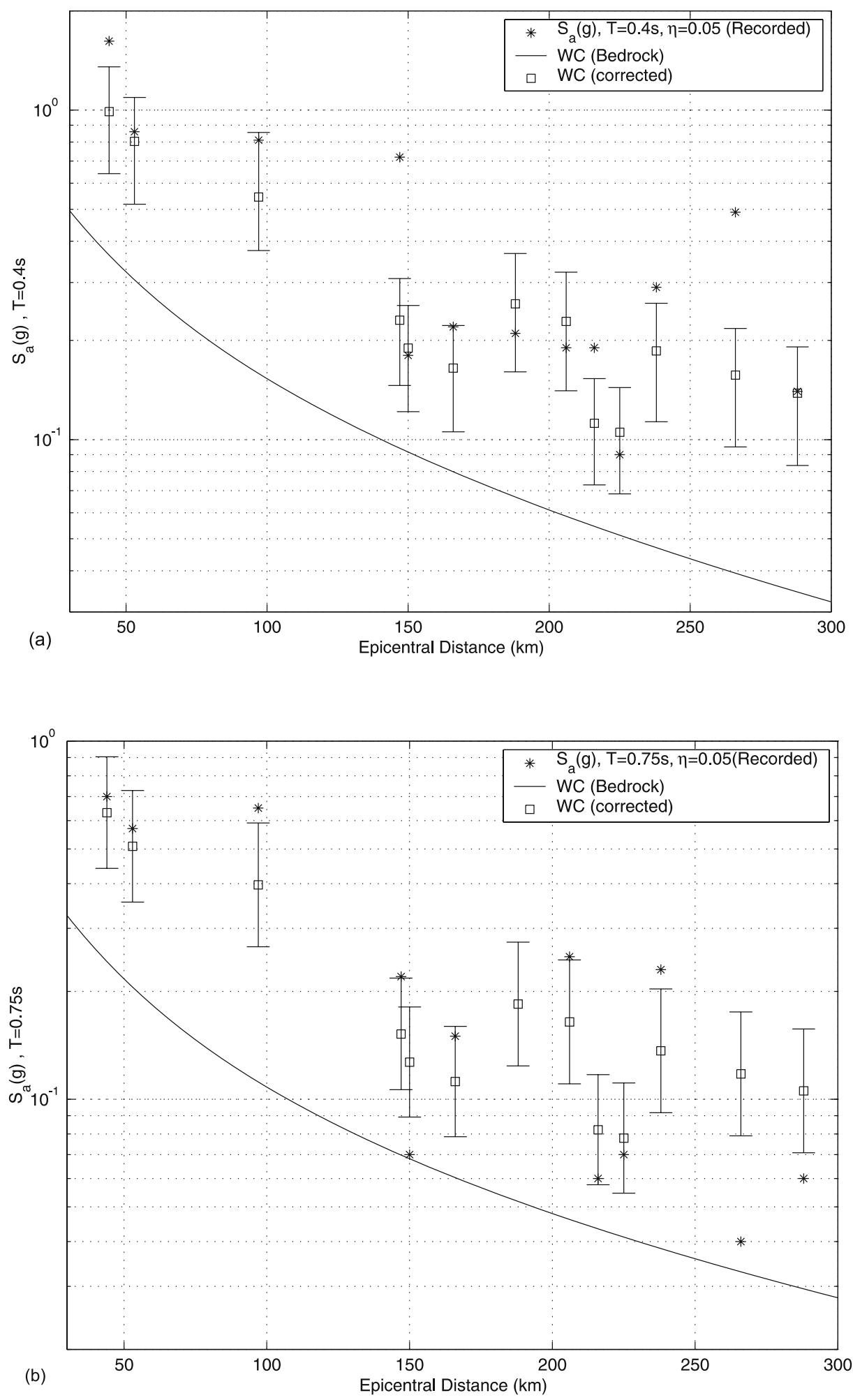

Figure 8. Comparison of $\mathrm{W}-\mathrm{C}$ attenuation corrected for soil conditions with recorded SRR data of Kutch earthquake 26 January 2001 (a) $M_{w}=7.7 ; T=0.4 \mathrm{~s} ; \eta=5 \%$ and (b) $M_{w}=7.7 ; T=0.75 \mathrm{~s} ; \eta=5 \%$. The vertical bands are 1 -sigma wide about the mean value.

at high frequencies, which is characteristic of intraplate regions. The differences observable in the figures are mainly attributed to the different quality factors, stress drop ranges and the definition of source-to-site distance. The differences in the spectral values between Atkinson and Boore (2006) and PI relation can be attributed to the point source assumption in the seismological model used in this 
Table 6(a). Site coefficients at $0.3 S$ natural period.

\begin{tabular}{cllllll}
\hline $\begin{array}{c}\text { Site } \\
\text { category }\end{array}$ & Case & $0.1 \mathrm{~g}$ & $0.2 \mathrm{~g}$ & $0.3 \mathrm{~g}$ & $0.4 \mathrm{~g}$ & $0.5 \mathrm{~g}$ \\
\hline A & Authors & 0.79 & 0.79 & 0.79 & 0.79 & 0.79 \\
& NEHRP & 0.8 & 0.8 & 0.8 & 0.8 & 0.8 \\
$\mathrm{~B}$ & Authors & 1.0 & 1.0 & 1.0 & 1.0 & 1.0 \\
& NEHRP & 1.0 & 1.0 & 1.0 & 1.0 & 1.0 \\
$\mathrm{C}$ & Authors & 1.32 & 1.33 & 1.33 & 1.34 & 1.35 \\
& NEHRP & 1.2 & 1.2 & 1.1 & 1.0 & 1.0 \\
$\mathrm{D}$ & Authors & 1.76 & 1.46 & 1.22 & 1.0 & 0.84 \\
& NEHRP & 1.6 & 1.4 & 1.2 & 1.1 & 1.0 \\
\hline
\end{tabular}

Table 6(b). Site coefficients at $1 S$ natural period.

\begin{tabular}{cllllll}
\hline $\begin{array}{c}\text { Site } \\
\text { category }\end{array}$ & Case & $0.1 \mathrm{~g}$ & $0.2 \mathrm{~g}$ & $0.3 \mathrm{~g}$ & $0.4 \mathrm{~g}$ & $0.5 \mathrm{~g}$ \\
\hline A & Authors & 0.84 & 0.84 & 0.84 & 0.84 & 0.84 \\
& NEHRP & 0.8 & 0.8 & 0.8 & 0.8 & 0.8 \\
B & Authors & 1.0 & 1.0 & 1.0 & 1.0 & 1.0 \\
& NEHRP & 1.0 & 1.0 & 1.0 & 1.0 & 1.0 \\
C & Authors & 1.20 & 1.23 & 1.26 & 1.29 & 1.32 \\
& NEHRP & 1.7 & 1.6 & 1.5 & 1.4 & 1.3 \\
D & Authors & 1.94 & 2.05 & 2.15 & 2.28 & 2.39 \\
& NEHRP & 2.4 & 2.0 & 1.8 & 1.6 & 1.5 \\
\hline
\end{tabular}

study. The standard error obtained here, is of the same order as reported by others in the past. Further evaluation of the spectral attenuation model for PI is possible by comparing it with recorded results of the Koyna (11 December 1967) and Kutch (26 January 2001) earthquakes. The Koyna earthquake was the first event in India with a near-source strong motion acceleration record. The instrument location was the basement of Koyna dam on hard rock nearly corresponding to an A-type site. In figure 7 the response spectrum computed analytically from the attenuation equations (8) and (10), is compared with the average of the response spectrum of the two horizontal components. The instrumental spectrum compares favourably with the predicted mean spectrum, with fluctuations within the sigma band. Recorded time history exhibits the presence of high frequencies (Krishna et al 1969), which is reflected well in the predicted spectrum. The Kutch earthquake produced data on structural response recorders (SRR) at thirteen stations. This directly gives $S_{a}$ at a particular period on the response spectrum corresponding to local site conditions. In figure $8(\mathrm{a}, \mathrm{b})$ SRR data for two natural periods, $0.4 \mathrm{~s}$ and $0.75 \mathrm{~s}$ at 5\% damping are compared with the present estimates corrected for actual soil conditions as reported by Cramer and Kumar (2003). Except at two stations, the overall comparison between the predictions and the observed values are favourable. The reasons for large deviations at the outlier points needs further investigations on local site conditions and accuracy of the records.

\section{Discussion}

In the absence of a sufficient number of instrumental data in PI, design response spectrum has to be estimated through simulation of seismological models. The advantage of this approach is that one can account for epistemic uncertainties associated with important parameters such as stress drop, focal depth, and corner frequency. The onedimensional nature of the model introduces a constraint on the hypocentral distance below which the results may not be applicable. This will not be a serious limitation in a region like PI, wherein the faults are deep and of short length. PI is not homogeneous with respect to the Q-factor and hence three different sets of results are presented in table $2(\mathrm{a}, \mathrm{b}, \mathrm{c})$ for better accuracy. The standard error $\sigma\left(\ln \varepsilon_{b r}\right)$ in the three cases is nearly equal. $S_{a}$ is not very sensitive to inter-regional variations except at large distances. Having a composite formula for attenuation of $S_{a}$ for the whole of PI has distinct advantages in preliminary engineering studies, but this makes the standard error 

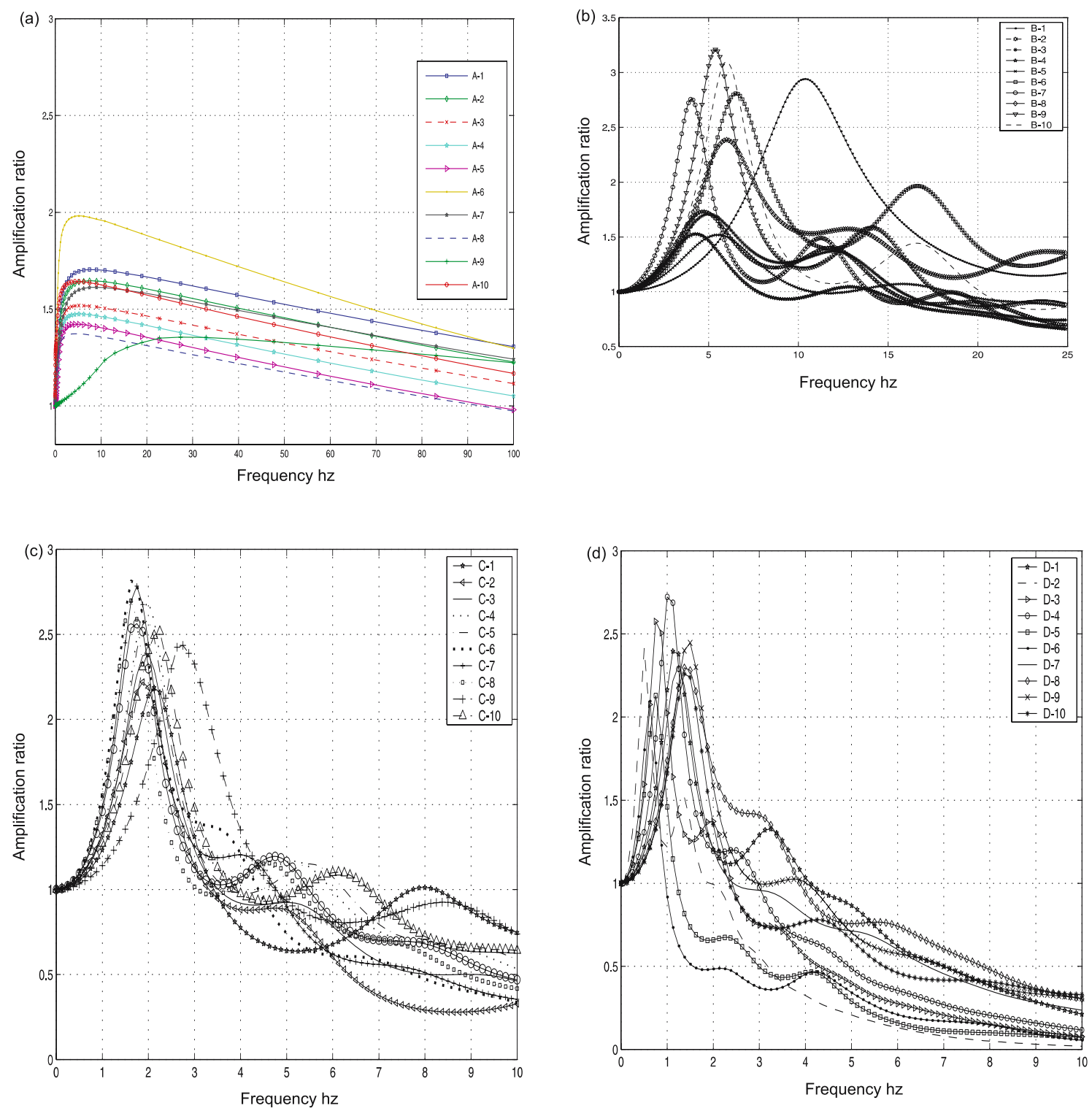

Figure 9. Frequency response functions $F(f)$ for A, B, C, D type site conditions in PI.

to increase as seen in table 3 . It has been verified that for the Koyna earthquake response spectrum, both the PI model and the regional $\mathrm{K}-\mathrm{W}$ model give almost the same results. However, recorded spectral attenuation data from Kutch earthquake matches better with the $\mathrm{W}-\mathrm{C}$ regional model than with the broad PI model. Hence, in situations where the location of the site is given or when an existing important structure such as a nuclear power plant has to be studied, the appropriate regional attenuations should be used. The single most important factor influencing response spectra is the local soil condition. As a help to incorporate this effect in $S_{a}$ estimates, here several different combinations of site conditions specific to PI in terms of $V_{30}$ are investigated. The transfer function $F(f)$ in equation (1) for A, B, C, D-type local site conditions, with ten samples in each group, is shown in figure $9(\mathrm{a}, \mathrm{b}, \mathrm{c}, \mathrm{d})$ to demonstrate the effects of soil layering. The progressive shift of the predominant high frequency peak in $S_{a}$ to lower frequencies can be accounted by modeling $F(f)$ realistically. As the nonlinear behaviour of soft soil layers come into effect, the surface PGA value may sometimes get reduced with respect to the bedrock value as seen in figure 4 . Here, it would be interesting to compare the present site coefficients with those given by NEHRP (BSSC 2001). Such a comparison is presented in tables 6(a) and 6(b) for two natural period values. B-type site is taken as the reference site with coefficient of unity at all periods. It is seen that the two sets of coefficients match closely for A-type sites. For C-type sites, the present values are higher than NEHRP 


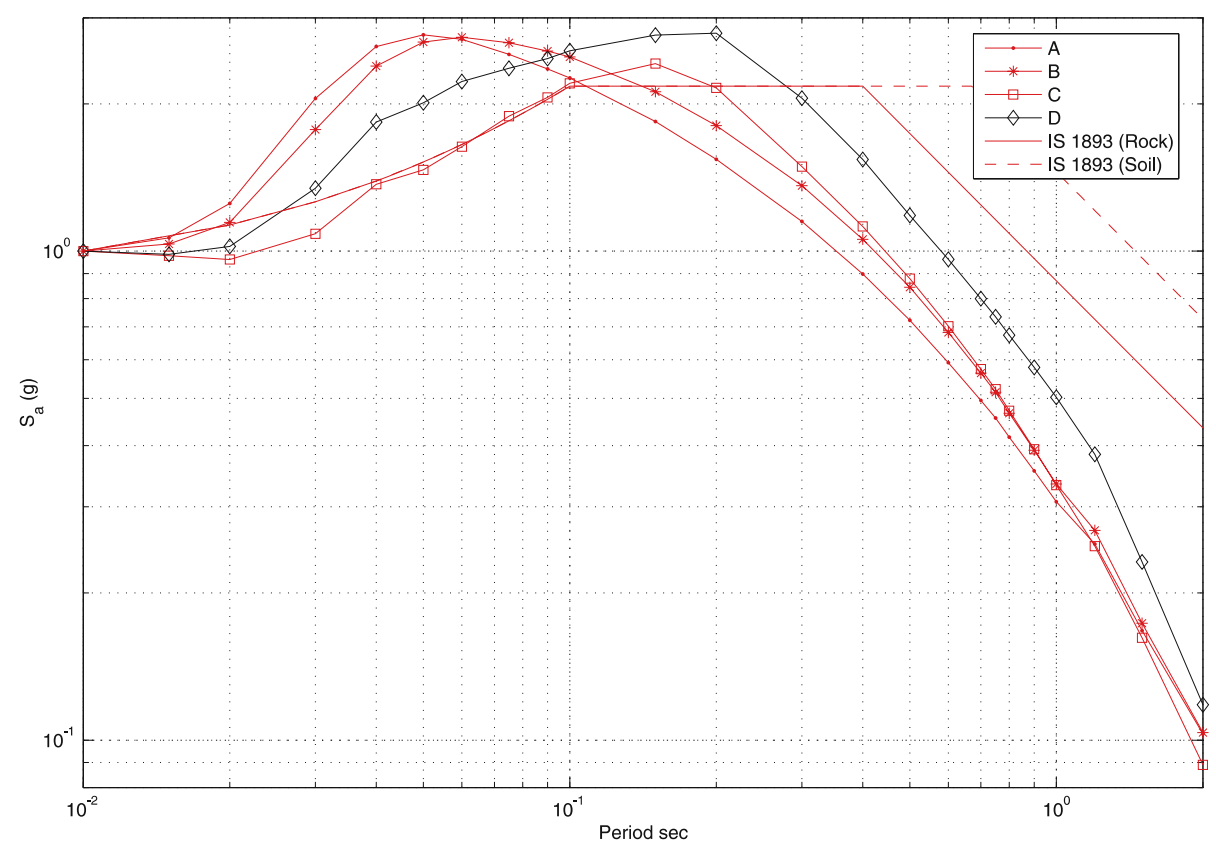

Figure 10. Comparison of present estimated analytical response spectra with design spectra recommended by IS-1893 $(\eta=5 \%)$.

values by $10 \%-30 \%$. On the other hand, at the long period point of $1 \mathrm{~s}$ the present coefficients are considerably less than the NEHRP values. The higher value obtained here at $0.3 \mathrm{~s}$ is tentatively attributed to the lower damping values as presumed following the data of Idriss and Sun (1992). For D-type sites the two results again match favourably within the range of standard error of equation (9). It may be noted here that similar trends are observed in the results of Hwang et al (1997) for central and eastern United States. Sites classified as E and F with very low $V_{30}$ values are susceptible for failure and hence are not considered here. Such sites demand more rigorous nonlinear dynamic analysis, not accounted for by the present one-dimensional site model. Engineers in India generally use the spectral shape recommended by the BIS code IS1893 (2002) scaled by a zonal factor presumably representing the expected PGA in the zone. The BIS code recommends normalized spectrum shape for rock and soil conditions as being valid all over India for all magnitudes and hypocentral distances. It is interesting to compare these code spectra with the present results. The normalized analytical spectral shape corresponding to equations (8) and (10) can be obtained by considering $M$ and $r$ as random variables. Here the moment magnitude $M$ is taken as exponentially distributed between 5 and 8 . The distance term is distributed as a uniform random variable between 30 and $300 \mathrm{~km}$. The average spectra is scaled to unit PGA and presented in figure 10 along with the recommendations of IS-1893 (2002). It is seen that the spectra recommended in the code have serious limitations as far as their applicability to PI is concerned. The rock site of IS code is between $\mathrm{C}$ and D-type with $V_{30}$ being less than $760 \mathrm{~m} / \mathrm{s}$. For rock sites that are commonly met in PI, the code spectrum underestimates seismic forces on high frequency structures. On the other hand, at soft soil sites the code overestimates forces on long period structures, such as tall buildings.

\section{Summary}

Understanding spatial variations of ground motion due to strong earthquakes is an important engineering problem. This is particularly so in assuring safety of important structures such as dams, bridges and nuclear power plants. Due to the scarcity of data, this problem is not tractable from purely instrumental records in intra-plate regions. The present paper addresses this issue with reference to PI through computer simulation based on a stochastic seismological model. A new empirical attenuation relation has been proposed for generating design response spectra for engineering structures in PI. The approach is validated by comparing analytical results of the present model with instrumental data of two strong earthquakes in PI. Results are presented in a form directly applicable in probabilistic seismic hazard analysis. Effect of local site condition is included in the investigation. A comparison of the present analytical results with the recommendations of the Indian code IS-1893 
brings out the limitations of the code as applied to an arbitrary site in PI.

\section{Acknowledgements}

The work presented here has been supported by Board of Research in Nuclear Sciences, Department of Atomic Energy, Govt. of India, through Grant No. 2002/36/5/BRNS. Thanks are due to Dr. D M Boore for his constructive comments and suggestions for improving the paper.

\section{References}

Atkinson G M and Boore D M 1995 New ground motion relations for eastern north America; Bull. Seismol. Soc. Am. 85 17-30.

Atkinson G M and Boore D M 2006 Earthquake GroundMotion Prediction Equations for Eastern North America; Bull. Seismol. Soc. Am. 96(6) 2181-2205.

Baumbach et al 1994 Study of foreshocks and aftershocks of the Intraplate Latur earthquake of September 30, 1993, India, Latur earthquake; Geol. Soc. India.

Boore D M 1983 Stochastic simulation of high-frequency ground motions based on seismological models of the radiated spectra; Bull. Seismol. Soc. Am. 73 1865-1894.

Boore D M and Atkinson G M 1987 Stochastic prediction of ground motion in Eastern North America; Bull. Seismol. Soc. Am. 4 460-477.

Boore D M and Boatwright J 1984 Average bodywave radiation coefficients; Bull. Seismol. Soc. Am. $\mathbf{7 4}$ $1615-1621$.

Boore D M and Joyner W B 1997 Site Amplification for Generic Rock Sites; Bull. Seismol. Soc. Am. 87(2) 327-341.

Boore D M 2003 Simulation of ground motion using the stochastic method; Pure Appl. Geophys. 160 635-675.

Brune J 1970 Tectonic stress and the spectra of seismic shear waves from earthquakes; J. Geophys. Res. $\mathbf{7 5}$ 4997-5009.

BSSC 2001 NEHRP Recommendations, Part 1: Provisions; prepared by the Building Seismic Safety Council for the Federal Emergency Management Agency (Report No FEMA 368), Washington, D.C., USA.
Campbell K W 2003 Engineering Models of Strong Ground Motion; In: Earthquake Engineering Handbook (eds) Chen W F, Scawthorn C S (Boca Raton, FL: CRC Press), 759-803.

Cramer C H and Kumar A 20032001 Bhuj, India Earthquake Engineering Seismoscope Recordings and Eastern North America Ground-Motion Attenuation Relations; Bull. Seismol. Soc. Am. 93 1390-1394.

Hwang H and Huo J-R 1997 Attenuation relations of ground motion for rock and soil sites in eastern United States; Soil Dynamics and Earthquake Engineering 16 363-372.

Hwang H, Lin H and Huo J-R 1997 Site coefficients for design of buildings in Eastern United States; Soil Dynamics and Earthquake Engineering 16 29-40.

Idriss I M and Sun J I 1992 User's Manual for SHAKE91, A computer program for conducting equivalent linear seismic response analyses of horizontally layered soil deposits.

Indian Standard, IS 1893 (Part I) 2002 Indian Standard, Criteria for earthquake resistance design of structures, Fifth revision, Part-I; Bureau of Indian Standard, New Delhi.

Iyengar R N and Raghu Kanth S T G 2004 Attenuation of strong ground motion in Peninsular India; Seismol. Res. Lett. 79(5) 530-540.

Joyner W B and Boore D M 1981 Peak horizontal acceleration and velocity from strong motion records including records from the 1979, Imperial valley, California Earthquake; Bull. Seismol. Soc. Am. 71 2011-2038.

Krishna J, Chandrasekharan A R and Saini S S 1969 Analysis of Koyna accelerogram of December 11, 1967; Bull. Seismol. Soc. Am. 59 1719-1731.

Mandal P and Rastogi B K 1998 A Frequency-dependent Relation of Codq $Q_{c}$ for Koyna-Warna Region, India; Pure Appl. Geophys. 153 163-177.

Saragoni G R and Hart G C 1974 Simulation of artificial earthquakes; Earthquake Eng. Structural Dyn. 2 249-267.

Singh S K, Ordaz M, Dattatrayam R S and Gupta H K 1999 A Spectral Analysis of the 21 May 1997, Jabalpur, India, Earthquake $\left(M_{w}=5.8\right)$ and Estimation of Ground Motion from Future Earthquakes in the Indian Shield Region; Bull. Seismol. Soc. Am. 89 1620-1630.

Toro G, Abrahamson N and Schneider J 1997 Model of strong ground motion in eastern and central North America: best estimates and uncertainties; Seismol. Res. Lett. 68 41-57. 